\title{
Critical Success Factors for Adopting Cloud Computing in the Pharmaceutical Manufacturing Companies
}

\author{
Mohammad Saleem Al - Shura ${ }^{1}$, Abdelrahim M. Zabadi ${ }^{2, *}$, Mohamad Abughazaleh ${ }^{3}$, \\ Marwa A. Alhadi ${ }^{4}$ \\ ${ }^{1}$ Management Department, College of Business \& Finance, the World Islamic Science \& Education University (WISE), Jordan \\ ${ }^{2}$ IT Department, College of Engineering, University of Business \& Technology (UBT), Saudi Arabia \\ ${ }^{3}$ IT Interface Department, Khalifa Industrial Zone Abu Dhabi, Kizad, United Arab Emirates \\ ${ }^{4}$ Computer Science Department, College of Engineering, Sana'a University, Yemen
}

Copyright $\mathrm{C} 2018$ by authors, all rights reserved. Authors agree that this article remains permanently open access under the terms of the Creative Commons Attribution License 4.0 International License

\begin{abstract}
Cloud computing is a model for enabling ubiquitous, easy, and on-demand network access to a shared aggregation of configurable computing sources. Adopting of cloud computing in the pharmaceutical manufacturing is influenced by a group of critical success factors. Therefore, this paper depends on the technological-organizational-environmental

(TOE)

framework to explore the factors that influence on cloud computing adoption by pharmaceutical industry firms in Jordan through proposing a model for Pharmaceutical Manufacturing Companies. Complexity, compatibility, relative advantage, top management support, firm size, technical readiness, competitive pressure, and trading partner pressure, are the eight critical success factors that have been tested. A survey was utilized to collect data from 16 pharmaceutical manufacturing firms in the capital of Jordan- Amman. Relevant hypotheses were developed and examined by multiple regression analysis. The results of the data analysis generally support the suggested model. In summary, the results of this research have shown that all above-mentioned factors were found to have a significant influence on adoption of cloud computing for the pharmaceutical industry in Jordan. This finding of adoption in cloud computing in the pharmaceutical industry will help firms to take into consideration their information for technologies investments.
\end{abstract}

Keywords Cloud Computing, Technology Organization - Environment (TOE) Framework, Technology Adoption, Pharmaceutical Industry, Information Technology (IT)

\section{Introduction}

Over the last 10 years, the technology industry has changed rapidly, and this change has appeared in the concept of the manufacturing industry because this sector is facing business challenges like concentrating on improving performance and the ability to control the cost of business doing. Therefore, business firms require updating their skills and technology in order to produce new services appropriate to the business needs and due to the rapid competition growth (Pauly, $M$, 2011)[1]. In today's business world, the ability of a firm to sustain a competitive feature is also a challenge according to the global and rapid growth of innovative technology; this competition is dynamic and crucial for upcoming business development in the economic globalization (Jin , 2007 ) [2].

Information technology (IT) has the ability to change the business context into planning and organized steps such as creating strategic opportunity and improving operational efficiency and effectiveness and this will happen through applying cloud computing technology. The cloud technologies have become the base for fundamental business innovation and new business models along with decreasing functioning costs. Cloud computing is the second trend of IT for governments, firms, and individuals to enhance their business processes in costless and availability features. Recently, pharmaceutical firms are trying to explore the benefits through the period of technology development. Pharmaceutical firms are known for its late adoption of new technologies. Before adopting any new technology; the industry thoroughly studies pros, cons, risks, and benefits in order to understand the base for this technology and how to avoid failure. But now, as firms are being forced to streamline their process and reduce costs, they are finding new ways to optimize complex processes and it is through adopting of the cloud computing. The advantages of the cloud "pay as you go" model, low capital investment, low run costs will drive innovation in 
products and bundled services quick to the market (Science, 2014)[3]. Developing in enterprise IT infrastructure can remove some of the barriers to participating in global marketing and assist Pharmaceutical firms to have an efficient business and compete in global markets. Many studies have attempted to investigate the adoption of new technologies from both individual and organizational perspective [ (Alshamaila, Y., et al, 2013); (Oliveira,T. et al, 2014); (S. S. Bharadwaj and P. Lal, , 2012)] [4]; [5];[6]. These studies have attempted to identify the factors that impact technology adoption and the relationship between these factors (Gangwar, H.,et al , 2015)[7]. In addition, in number of studies, technology adoption theories/frameworks have been utilized to support the investigation of cloud computing adoption effect on organizational performance [ (Alshamaila, Y., et al, 2013); (G. Chao et al., 2014)] [4]; [8].

The Jordan's pharmaceutical industry is a pioneer exporting sector due to its high quality and excellent reputation. Therefore, $81 \%$ of the production is exported to foreign business areas. Moreover, these industries are now distributed into worldwide and to more than 60 countries whereas $90 \%$ of their exports are going to Arabic countries. The literature on cloud computing adoption focuses primarily on technology adoption in developed countries. Few studies (if any) include an empirical study that carried out to on investigation cloud computing adoption in Jordan context at the organizational level. There is only one study which investigates the effect of cloud computing in the Jordanian hospitals (Osama Harfoushi et al., 2016)[9].

However, there is still an urgent need to analyze the adoption of this technology in several business sectors in order to have a better understanding of cloud computing. The purpose of this research study is to analyze and describe critical success factors that impact cloud computing adoption in Jordanian Pharmaceutical manufacturing firms utilizing the framework developed by Tornatzky and Fleischer (1990) for adopting IT efficiency in organizations and implementing technical innovations. The study is structured as follows; Section 2 provides a theoretical background of cloud computing and TOE framework; Section 3 presents the previous related works; Section 4 outlines the research framework and hypotheses development; Section 5 present the methodological approach taken; Section $\mathbf{6}$ show the data analysis and results; Section 7 provide a discussion of results, finally, Section 8 draw a conclusion and future work.

\section{Background}

\subsection{Cloud Computing}

It is an ever-increasing phenomenon in the domain of information and communication technology (ICT), it has acquired growing attention from different business firms to overcome some obstacles and the business barriers that faced. Cloud Computing is defined by the US National Institute of Standards and Technology (NIST) as: "A model for enabling ubiquitous, convenient, on-demand network access to a shared pool of configurable computing resources (e.g. networks, servers, storage, applications, and services) that can be quickly provisioned and send out with less managerial effort or service provider interaction"[ (Mell and Grance, 2011); (M. Amini and N. Sadat Safavi , 2013)][10]; [11]. It promotes the availability and as well includes five fundamental features: Self-service on demand, access to broad networks, pooling of resources, swift flexibility, and services measured [ (M. Amini and N. Sadat Safavi , 2013); (Vouk, M, 2008)[11]; [12].Software as a Service (SaaS), Platform as a Service (PaaS), and Infrastructure as a Service (IaaS) are the three cloud computing services models (M. Zhou and R. Zhang, 2010)[13].Furthermore, Private, Public, Community, Hybrid the four deployment models of cloud computing (M. Amini and N. Sadat Safavi , 2013)[11]. Many advantages are affording by cloud computing to organizations for example but not limited to supplying the opportunity to access on-demand IT services utilizing Internet technologies on a free or pay-per-use basis, helps organizations to evolve their technological and strategic agility, also, increase the level of responsiveness in the business environment globally (Son et al. , 2011)[14].Thus, cloud computing reflects "a sea change-a deep and permanent shift in how computing power is created and used" (McAfee, A, 2011)[15]. Finally, the cloud computing is not only about a technological improvement of data centers, but also an essential change in how information technology (IT) is provisioned and utilized, in a time where competition in a business market increasing rapidly and all companies are trying to be up to date so as to produce new services and products for their business needs.

\section{2. (TOE) - Framework}

The conceptual framework that is developed in this research study is based on the concepts derived from Diffusion of Innovation (DOI) theory and TOE framework. DOI characterizes five factors that impact on the adoption of novel ideas; it is the relative advantage, compatibility, complexity, trialability, and observability (Pauly, M , 2011)[1]. TOE frame was developed by Tornatzky and Fleischer in 1990 to explore innovation adoption at the organization level (Oliveira and Martins , 2010)[16]). In addition, the TOE classifies these factors which influence on technology adoption in the organization into three groups namely, technological, Organizational, and environmental context (Alpar and Reeves, 1990) [17]. It has been claimed that utilizes of these three categories of TOE framework gives the advantage over other technology adoption theories/models ( Low, C., et al, 2011)[18]. 
These factors constitute eight predictors for adopting cloud computing as highlighted in the following section and as well in Figure1.

\section{Related Works}

Regarding cloud computing, we have picked diverse methods to demonstrate what factors enable or disable firms to adopt cloud computing. Many research studies have been conducted in an attempt to understand different factors that are prospective to impact the adoption of different new technologies [ (Jin , 2007); (Cegielski et al., 2012)] [2]; [19]. For example, ( Low, C., et al, 2011)[18], investigated the impact of the factors (relative advantage, complexity, compatibility, top management support, firm size, technology readiness, competitive pressure, and trading partner pressure) on the adoption of cloud computing in high-tech companies, the results revealed that five of these factors(relative advantage, top management support, firm size, competitive pressure, and trading partner pressure) are significantly influenced the adoption of cloud computing.

Lian, J.W., Yen, D.C. and Wang, Y.T. (2014) studied the impact of different factors on the adoption of cloud computing in Taiwan's hospitals, the study indicated that the most factors were "data security, perceived technical competence, cost, top management support, and complexity" (Lian, J.W., et al , 2014)[20]. Alshamaila, Y., Papagiannidis, S. and Li, F. (2013) "examined the effect of the TOE framework on the adoption of cloud computing in Small and Medium Enterprises, the factors were technology factors ("relative advantage, uncertainty, compatibility, complexity, and trainability"), organizational factors ("size, top management support, innovativeness, and prior IT experience"), and environmental factors ("competitive pressure, industry, market scope, supplier efforts and external computing support"). The results showed that most of these elements had a significant effect on the adoption of cloud services in these companies (Alshamaila, Y., et al, 2013)[4], the competitive pressure was the only factor that was not found to have any contribution in the process of adopting cloud computing.

Moreover, Gutierrez, A., Boukrami, E. and Lumsden, R. (2015) used the TOE framework to determine which factors impact the decision of managers to adopt cloud computing in the United Kingdom, the results showed that the factors ("competitive pressure, complexity, technology readiness and trading partner pressure) had a positive impact on the adoption of cloud computing (Gutierrez, A., et al , 2015)[21]. A study was conducted by (Alkhater, N., et al , 2014)[22] with the aim of identifying the factors with the most influence on the intention of organizations to adopt cloud services, it was noted that between the four dimensions suggested to impact the adoption of cloud computing, the most significant one was technology, followed by human, organizational, and environmental factors, also, the study found that the factors of availability, reliability, security, privacy, and others had a significant impact on the decision to adopt cloud computing. Only trading partner pressure which not.

Gangwar, H., Date, H. and Ramaswamy, R. (2015), also attempted to understand which factors influenced the adoption of cloud computing in firms, the researchers used an integrated model composed of both Technology Acceptance Model (TAM) and TOE factors in addition to two mediating variables including perceived usefulness and perceived ease of use to explain the variation in the dependent variable, intention to adopt cloud computing. The findings of the study suggested that relative advantage, compatibility, complexity, organizational readiness, top management commitment, and training and education were the most important variables affecting the adoption of cloud computing (Gangwar, H.,et al , 2015)[7].

\section{Research Framework and Hypotheses Development}

The current research study model in figure 1 is proposed by TOE framework. TOE framework has a strong theoretical basis, credible empirical support to investigate IS / IT innovation adoption (Melville N, Ramirez R., 2008)[23]. This framework proposes that adoption of information technology by organizations and it is affected by Technological, organizational, and environmental factors (Melville N, Ramirez R., 2008)[23]. Thence, the variable of major interest is the adoption of cloud computing" which is the dependent variable, while technological, organizational, and environmental factors are the independent variables applied to demonstrate the variance in the dependent variable. These critical success factors were derived from a previous research which conducted about critical success factors on IT adoption. Research Model is depicted in figure 1. In the next subsections, the definition of each factor is presented. Over and above, the variables have been offered with each factor are specified, followed by hypotheses of the research. 


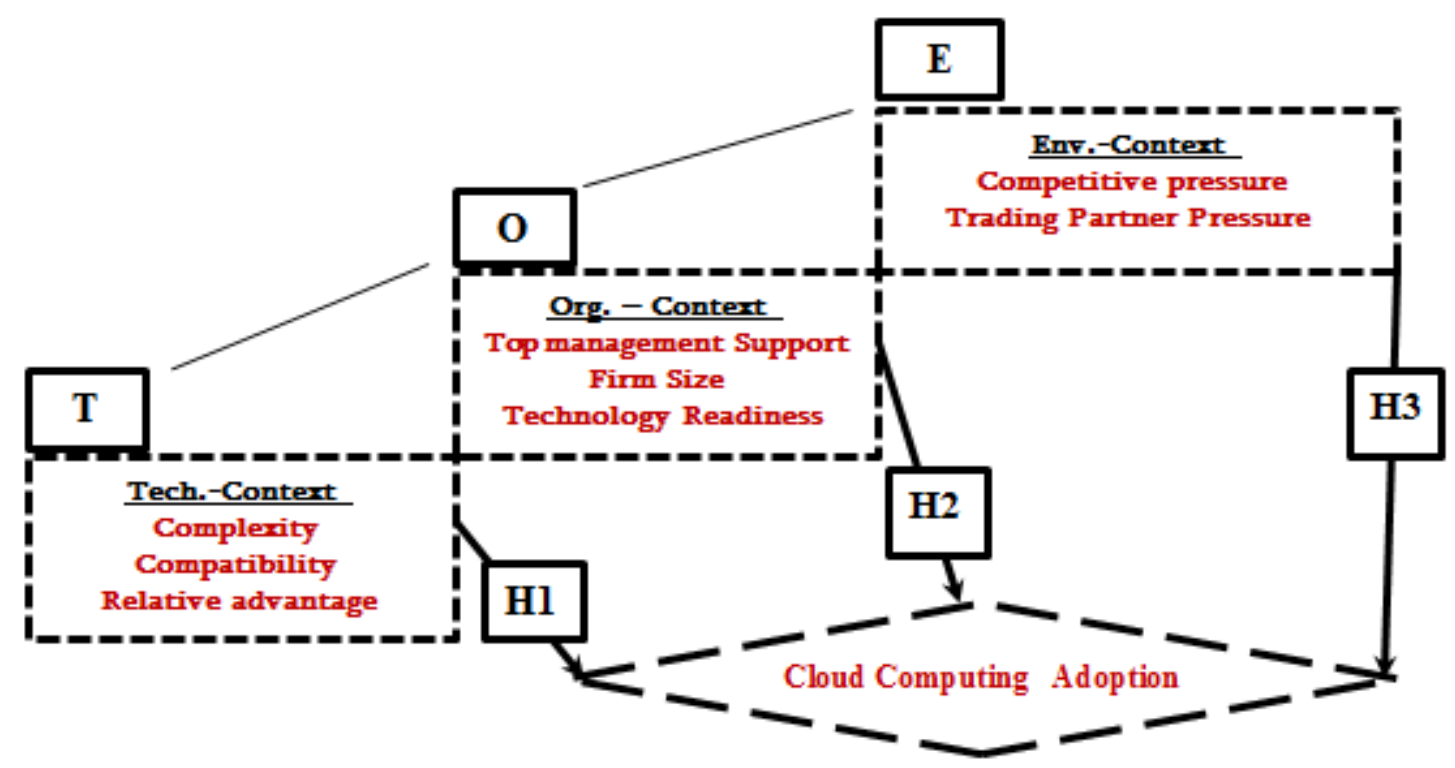

Figure 1. The proposed research model for cloud computing adoption in Pharmaceutical Manufacturing Companies

\subsection{Technology Context (Tech. - Cont.)}

The technology context refers to the technological characteristics (infrastructure) available in the firm for innovative technology adoption (Alshamaila, Y., et al, 2013)[4] that contain the structural aspects and the specialized human resources. The specialized human resources are those in an organization with the knowledge and skills to implement the services (e.g., employees with computer skills, IT specialists) (M. W. Wang et al., 2007)[24].The technology context represents the technical issues that will influence the decision on the adoption of Cloud computing. Based on the literature review, three variables have been suggested in the T- Cont. and they are complexity, compatibility, and relative advantage. In the following, these three variables are described in detail.

\subsubsection{Complexity}

(Sonnenwald et al., 2001)[25], defined technology complexity as "the level of perceived difficulty of understanding and using technology usage. It is associated with integrated cloud infrastructure, the time taken to implement the task, design interface, capacity of transfer the data, and system functionality (Gangwar, H.,et al , 2015)[7].Adoption of new IT innovations will be less of a use even if it seems difficult (Rogers, E, 2003)[26]. Also, adopting of new cloud computing technologies make the organization faces many challenges such as changing the processes that interact with its business systems (Alshamaila, Y., et al, 2013)[4].These adopted technologies should be user-friendly, easy to harness, and manageable so as to increase the opportunities for its adoption (Berman et al. , 2012)[27]. However, cloud computing is still in its beginning stages and organizations afraid and hesitate of the decision making an adoption (Dwivedi and Mustafee , 2010)[28] technology considered complex if it takes too much effort and time to be learned; or if the user should spend too much time to accomplish the usual duties (Alshamaila, Y., et al, 2013)[4]. The bottom line, in the context of cloud computing adoption the system complexity level, has a significant impact on the adoption of cloud computing.

\subsubsection{Compatibility}

Compatibility refers to "the degree, to which an innovation is perceived as consistent with the current values, needs of potential adopters and their previous experiences" (Rogers, E, 2003)[26]. Compatibility considered as a vital determinant of cloud computing adoption innovations (F. Thiesse at al., 2011)[29].Perceived compatibility takes into account whether behavioral patterns, present values, and organization experiences and its employees are consistent with a new technology (Peng et al. , 2012)[30].Increasing the compatibility among an innovation and adopter's needs will facilitate the integration of technology within the organization and business functions (Osama Harfoushi et al., 2016) [9]. According to (Gutierrez, A., et al , 2015)[21], cloud computing permits firms to keep up with new innovative technology. Technology compatibility with existing systems, organizational values and beliefs motivate organizations to adopt with cloud computing.

\subsubsection{Relative Advantage}

"Relative advantage is defined as" the level to which a technological factor has more benefits that advantage to the organization" (Rogers, E, 2003)[26].Innovations in cloud computing that have a clear, unambiguous feature in generating a strategic effectiveness (increasing sales for instance) and operational efficiency (reducing operational costs for example) has a higher motive for adoption ( $\mathbf{T}$. Greenhalgh et al., 2004)[31]. Cloud computing leads to 
radical changes in the existing practices and processes as well as improving the performance generally (P. Ifinedo, 2011)[32].Previous studies have found that relative advantage is an important determinant for cloud computing adoption; therefore, it is crucial to explore this concept in the context of cloud computing adoption and its effectiveness on organizational performance (S. S. Alam, 2009)[33].Firms should weigh the anticipated results from adopting of cloud computing, this occurs when firms perceived a relative advantage from that innovation.

Many advantages that will assist organizations from adapting of cloud computing: accelerate business communication, active coordination between organizations, improve communication with customers and consumers, and quick access to the market information, another benefits include reduced costs, scalability, flexibility, mobility, pay-per-use, and shared resources [ ( Low, C., et al, 2011); (Miller, M, 2008)][18];[34].Moreover, it improves the quality, productivity and company's performance. As a result of the above-mentioned benefits, the relative advantage has a positive impact on adoption of cloud computing. Based on the above discussion, we will propose that technological content (Complexity, Compatibility, and relative advantage) will impact the adoption of cloud computing in Jordan's pharmaceutical manufacturing firms.

\subsection{Organizational Context: (Org. - Cont.)}

Based on the literature review, three variables have been proposed in the Org. - Cont., they are top management support, firm size, and technical readiness. In following subsections, these three variables are described in detail:

\subsubsection{Top Management Support}

Top management support plays an important role in the decision of adoption of cloud computing which involves resources and infrastructure saving, services simulation, procedures re-engineering ( Low, C., et al, 2011)[18]. Cloud computing encourages the top management to implement the change, estimate the required resources for its adoption. Thus, the degree of support to adopt the technological innovations for business use depends on top management support. As proposed by the latest reviews of the IT adoption literature, top management support is one of the most top forecasters for cloud computing innovation adoption (Azam et al., 2014)[35].Furthermore, it has been suggested by earlier studies on the adoption of IT innovation, that top management support has a critical influence on the organization's decision for cloud computing adoption based on the TOE framework [ (Feuerlicht and Govardhan, 2010); (Lin and Chen, 2012)][36];[37].Top management that understands the benefits of cloud computing will likely allocate the needful resources for its adoption and influences on the organizational members to implement the change
(Alshamaila, Y., et al, 2013)[4].

\subsubsection{Firm Size}

Firm size is another factor that can affect the adoption of cloud computing. Concerning with innovative adoption, big firms have more chances than small and medium firms. In spite of the fact that they are more adaptable, previous studies indicated those small enterprises and some of the medium enterprises do not willing to accept/adopt new technologies (Lippert and Govindarajulu , 2006)[38]. The size of a firm is an important factor that will assure the adoption of cloud computing as a technological innovation ( Low, C., et al, 2011)[18]Accordingly, the firm size is considered as a primary base towards intention of accepting technology innovations according to the IDT/DOI theory by Rogers (1995) (Lippert and Govindarajulu , 2006)[38]. The firm size impacts on the adoption of IT innovations such as cloud computing which proposed by the assessment of the studies based on a TOE framework (Hsu et al. , 2006) [39].

\subsubsection{Technical Readiness}

The adoption of any new technology is influenced by organizations' technical readiness, which means the technology infrastructure and IT human resources [ (Oliveira and Martins , 2010); (To and Ngai, 2006)] [16];[40]. Implemented network technologies and enterprise systems which offer a platform on which the cloud computing applications can be built is referred by technological infrastructure (Azam et al., 2014)[35].The implementing of cloud computing is correlated with IT applications that provided with knowledge and human resources' experience in IT. Also, cloud computing services can become a part of the value of chain activities in the organization only if it has the needful infrastructure and technical competence. Hence, firms that have a technological readiness and capability will be more willing for the adoption of cloud computing ( Low, C., et al, 2011)[18]. As a result, firms with a higher degree of technology readiness are in the best position regarding cloud computing adoption. Accordingly, we will hypothesize that organizational content (Top Management Support, Firm Size, and Technical Readiness) will influence the adoption of cloud computing in Jordan's pharmaceutical manufacturing firms.

\subsection{Environmental Context (Env. - Cont.)}

Env. - Cont. refers to "an organization's industry, competitors, and government policy or intention" ( Low, C., et al, 2011)[18]. This factor covers a small environment where the organization runs their business including industry market as well as technology service providers (Gutierrez et al., 2015)[21]. The Env - cont. utilized in this research study contain competitive pressure and trading partner pressure as follows: 


\subsubsection{Competitive Pressure}

According to (Laforet, S, 2011)[41], competitive pressure is "the degree level of pressure which firms can encounter from their competitors in the same industry scope. Competitive pressure can play a positive role in the adoption of any new technology because it influences the performance and competency (Ramdani and Kawalek, 2009)[42].As well, adopting technology assists firms in changing the competitive environment in various methods such as industry structure and outperforms competitors (Osama Harfoushi et al., 2016)[9].Cloud computing can improve the operating effectiveness, data accuracy, and lowering costs ( Low, C., et al, 2011)[18]. Therefore, firms that are initially adopting cloud computing are expected to gain benefits in terms of competitive advantage and survival (Gangwar, H.,et al , 2015)[7]. In Jordan, the pharmaceutical industry is witnessing strong competition locally and internationally and enjoys a good reputation.

\subsubsection{Trading Partner Pressure}

In cloud computing, trading cloud computing, trading partners relate to cloud services providers'. Firms rely on the experience and skills of trading partners when they looking to adopt of cloud services generally regardless of size (Osama Harfoushi et al., 2016)[9].The decision of whether to adopt a new information technology innovation or not is influenced by prior history and bygone projects of a trading partner (Gutierrez et al., 2015)[21].Firms that willingness to adopt cloud computing services is discomforted about the capability of service providers to ensure the availability of data when needed. To ensure the desired level of availability, service level agreements and a combination of precautionary measures can be used. Security is another concern of organizations when they decided to use cloud computing (Osama Harfoushi et al., 2016)[9].

Cloud computing security is more than exactly authenticity, authorization, and accountability; it is also relevant to data protection, disaster recovery, and business continuity (Alshamaila, Y., et al, 2013)[4]. Privacy and confidentiality also related to security because service providers have access to all the data ( Low, C., et al, 2011)[18]. The trading partners' experiences in cloud computing impact the organization's decision for adoption. This component is, therefore, an important and influential factor in the adoption of cloud computing in pharmaceutical manufacturers and other business enterprises. Consequently, we will propose that environmental content (Competitive Pressure and Trading Partner Pressure) will affect the adoption of cloud computing in Jordan's pharmaceutical manufacturing firms.

\section{Research hypotheses:}

Based on the research framework as well as the study's proposed model, the following three null hypotheses were formulated and be tested:

Hypothesis One (H1): The technology content does not impact the adoption of cloud computing in Jordan's pharmaceutical manufacturing firms.

Hypothesis Two: (H2): The organizational content does not impact the adoption of cloud computing in Jordan's pharmaceutical manufacturing firms.

Hypothesis Three: (H3): The environmental content does not impact the adoption of cloud computing in Jordan's pharmaceutical manufacturing firms.

\section{Methodology}

To evaluate how TOE framework factors that impact the cloud computing adoption in Jordan's pharmaceutical firms, a quantitative method was conducted. Data will be collected through designed questionnaire through reviewing the literature and collect initial information about cloud computing adoption so as to help these enterprises to gain a better understanding about how these three factors impact on their adoption to cloud computing model. The population of the current study included 16 big pharmaceutical manufacturing companies that work in the healthcare sector in Jordan. 250 questionnaires were distributed to the employees working in the IT department in the targeted companies. The companies were randomly selected based on [ (Sekaran and Bougie, 2013); (Sekaran, U ， 2003)][43];[44] sampling method; the employees were being selected from each of randomly selected companies to represent the sample used in this research study[ (Sekaran and Bougie, 2013); (Sekaran, U , 2003) $[43] ;[44]$ ].The sampling scope refers to the set of people/firms from the targeted population that has the change to be selected ( J. Fowler and J. Floyd, 2008)[45]. 230 were returned, 6 of those were discarded because they were in incomplete. 224 found usable for this study with response rate of $(89.9 \%)$.

\subsection{Variable Measurement}

Three factors (TOE) that impact the adoption of cloud computing will be tested through 8 critical success factors (variables); Tech. - Cont., which includes 3 constructs; complexity, compatibility, and relative advantage, as suggested by (Feuerlicht and Govardhan, 2010)[36] measured by 8 items. Org. - Cont. that includes 3 constructs; top management support, firm size, and technology readiness are also derived from (Gutierrez, A., et al , 2015)[21] measured by 7 items, Env. - Cont. Includes 2 constructs; competitive pressure, trading partner pressure are also derived from (35) measured by 6 items. Finally, cloud computing adoption was measured through 4 items based on a study conducted by (Tweel, A, 2012)[46].To test the hypotheses related to this research paper, the collected data will help to examine the relationship between the variables. 


\section{Data Analysis}

In order to examine the effect of TOE factors on the adoption of cloud computing, a Five - points Likert - type scale of agreement, running from strongly disagree $=1$ and strongly agree $=5$ were used. Reliability and validity analyses were conducted, in addition to the multi collinearity test; multiple regression analysis was conducted to test the research hypotheses. The data were analyzed using Statistical Package for Social Sciences (SPSS) version 17. A measure of multiple regression analysis will be conducted, in addition to reliability and multi-collinearity tests. The results provide the foundation for accepting/rejecting the hypotheses.

\subsection{Validity and Reliability}

Validity and reliability are two important measurements that determine the quality and usefulness of collected data. The validity is concerning accuracy, and whether the instrument measures what it is sought to evaluate. Reliability is about precision; it is used to check the consistency and stability of the questionnaire. The researcher(s) depended on scales and items that were previously developed and used by other researchers with similar interests. Moreover, a draft copy of the questionnaire was reviewed by four academic lecturers who have sufficient knowledge and experience in this scope to make sure that each item is measuring what is expected to measure and to avoid any ambiguity or complexity in the phrasing of the items. The reliability of the research instrument was measured by Cronbach's alpha coefficient. According to (Hair Jr et al., 1998)[47], the values of all indicators or dimensional scales should be above the recommended value of 0.60 .The results of Cranach's alpha for the independent and dependent variables presented in Table1. Cronbach's alpha coefficients of all the tested variables are above 0.60 acceptable level of internal consistency, and suitable for further analysis which is generally acceptable in scientific research.

Table 1. TOE model Cronbach's alpha Values

\begin{tabular}{|c|c|c|}
\hline Variable & No. of items & $\begin{array}{c}\text { Cronbach's alpha } \\
\text { Values }\end{array}$ \\
\hline Tech.- Cont. & 8 & 0.685 \\
\hline Org. - Cont. & 7 & 0.754 \\
\hline Env. - Cont. & 6 & 0.709 \\
\hline $\begin{array}{c}\text { Adoption of cloud } \\
\text { computing }\end{array}$ & 4 & 0.662 \\
\hline
\end{tabular}

\subsection{Hypotheses Testing Results}

The purpose of this research study is to examine the effectiveness of critical success factors of TOE framework on the adoption of cloud computing in Jordan's pharmaceutical manufacturing firms. Accordingly, to test the study hypotheses, multiple regressions were utilized. Further, the level of significance ( $\alpha$-level) was selected to be $(0.05)$ and the probability value (p-value) obtained from the statistical hypotheses test is considered to be the decision rule for rejecting the null hypotheses (Creswell, J , 2009)[48]. If the $p$-value is $\leq$ to $\alpha$-level then, the alternative hypothesis will be accepted (supported) and the null hypothesis will be rejected. If the p-value is $>$ the $\alpha$-level, the alternative hypothesis will not be supported and the null hypothesis cannot be rejected. In addition, the normality of the independent variables and the loss of the multi co-linearity issue (i.e. the situation of multiple regression in which the independent variables are themselves highly correlated) were checked. As suggested by (Pallant, J , 2005)[49], most of the figures should be within the adequate domains of normality. For this aim, tolerance and Variance Inflation Factor (VIF) was investigated; a VIF value of 5 or 10 and above, and a tolerance of less than 0.20 indicates that variables are multicollinearity (the case in which two or more explanatory variables in multiple regression are highly linearly related). Table 2 shows the results.

Table 2. Variance Inflation Factor (VIF (and Tolerance for the independent variables.

\begin{tabular}{|c|c|c|}
\hline Variables & $\begin{array}{c}\text { Variance Inflation } \\
\text { Factor(VIF( }\end{array}$ & Tolerance \\
\hline Tech. - Cont. & 1.417 & 0.715 \\
\hline Org. - Cont. & 1.574 & 0.629 \\
\hline Env. - Cont. & 1.413 & 0.698 \\
\hline
\end{tabular}

It can be noticed that VIF limits between 1.413 and 1.574 which are well-below 5 as revealed in the above table. Moreover, the tolerance figures limit between 0.629 and 0.715 which are greater than 0.20 . These factors show that there is no directory of multicollinearity issue in the regression model. In addition to the VIF and tolerance figures, Pearson Correlation Matrix was determined for the independent variable contexts to check out the correlation between them as depicted in table 3 .

Table 3. Pearson Correlation Matrix

\begin{tabular}{|c|c|c|c|}
\hline Variables & \multicolumn{3}{|c|}{ Pearson Correlation } \\
\hline & T - Factor & O - Factor & E- Factor \\
\hline Tech. - Cont. & & $\mathbf{0 . 5 3 4}$ & $\mathbf{0 . 4 3 7}$ \\
\hline Org. - Cont. & & & $\mathbf{0 . 5 0 3}$ \\
\hline Env. - Cont. & & & \\
\hline
\end{tabular}

The figure of 0.75 and up indicates a high correlation between the variables according to (Sekaran, $\mathbf{U}, \mathbf{2 0 0 3}$ ), [44]. The outcomes in the above table, are all below 0.75 , and thus don't point out a high correlation between the variables. Therefore, these results likewise present that there is no index of multicollinearity problem. The results of examining the three hypotheses regarding the effect of TOE framework components (Tech.; Org.; and Env. ;) on the adoption of cloud computing are depicted in table 4 . 
Table 4. Result for the study model (b).

\begin{tabular}{|c|c|c|c|c|c|c|c|}
\hline Variables & $\mathbf{R}$ & $\mathbf{R}^{\mathbf{2}}$ & $\mathbf{F}$ & $\operatorname{Sig}(\mathbf{f})$ & $\boldsymbol{\beta}$ & $\mathbf{t}$ & $\operatorname{Sig}(\mathbf{t})$ \\
\hline Tech. - Cont. & $0.435^{\mathrm{a}}$ & 0.179 & 15.989 & $0.000^{\mathrm{a}}$ & 0.219 & 2.915 & 0.003 \\
\hline Org. - Cont. & & & & & 0.175 & 1.479 & 0.138 \\
\hline Env. - Cont. & & & & & 0.209 & 2.844 & 0.005 \\
\hline
\end{tabular}

${ }^{a}$ Predictors: T- Cont. O - Cont. E - Cont. ${ }^{b}$ Dependent variable: adoption of cloud computing.

Since the value of multiple correlation coefficients is $\mathrm{R}=$ 0.435 , so, there is a positive correlation between TOE framework components and adoption of cloud computing as manifested in the table above. The value of $\mathrm{R}^{2}$ (adjusted) relates to the model generalizability. It allows the researchers to generalize the findings taken from the respondents to the total population. In this case, it equals to 0.179 . Also, the figures showed that F- ratio for these data is equal to 15.989 , which is statistically significant at $p<$ 0.05 . Thus, we conclude that there is a statistically significant impact of TOE framework components on the adoption of cloud computing. The $\beta$ 's value indicates to the individual contribution of every predictor (independent variable) to the model if other predictors are held to be constant. Table 4, revealed the standardized coefficients for every TOE framework dimensions. The figure of $\beta$ for Tech. - Cont. is 0.219 , Org. - cont. is 0.175, and Env. Cont. is 0.209 which all are positive. The level of influence of these dimensions depends on the $\beta$ value (i.e. higher $\beta$ value is the higher impact on the adoption of cloud computing (dependent variable). It can be concluded from the values of $\beta$ that the variable that has the highest contribution to the model is Tech. - cont.; Env. - cont.; Org. - cont. respectively.

\section{Discussion}

The main aim of conducting this research was to determine whether the factors suggested by the TOE framework affected the adoption of cloud computing. The results indicate that the three (TOE) factors have a positive significant impact on the adoption of cloud computing with different levels in Jordanian Pharmaceutical manufacturing firms, and found out that the technology factor had a positive significant impact on the adoption of cloud computing. Therefore, (H1) "the technology content does not impact the adoption of cloud computing in Jordan's pharmaceutical manufacturing firms" was rejected. Further, it was found that this content had the most effect on the adopting of new IT innovation (i.e. cloud computing). This conclusion supports the findings of researchers [(Oliveira,T. et al, 2014); (Lin and Chen, 2012)] [5]; [37]. On another hand, complexity plays an important role in the context of cloud computing adoption. Many firms still have some anxiety and fears about investing in new IT innovations like cloud computing.

Compatibility is another reason why technology is an important factor to take into consideration when adopting cloud computing. It is necessary to realize if the technology is compatible with the current infrastructures in the firm, also if it is compatible with current values and adopters' needs (Gangwar, H.,et al , 2015)[7].Cloud computing must be compatible with IT development environment, business needs, and company's policy (36). Therefore, several steps should be taken to change existing processes to meet compatibility of cloud solutions in the organization's infrastructure. [ (Ross, 2010); (Gutierrez, A., et al , 2015)][50]; [21], declared that compatibility was not considered and crucial motivational factor for adoption of cloud computing not compatible with the findings of this research study.

The third component of Tech. - cont. is a relative advantage. It has been suggested that when firms perceive a relative advantage from an innovation, they are likely to adopt it (Lee, J., 2004)[51].The technology of cloud computing has different benefits (a relative advantage) such as mobility, flexibility, resource sharing, and cost reducing (Sultan, N. , 2011)[52]. Cloud computing services can make firms more effective (Alshamaila, Y., et al, 2013)[4]. Organizations demand a confirmation that the real advantages of cloud computing adoption are feasible before an adoption can be considered. This could be particularly important when it constrained by limited budgets ( J. Fowler and J. Floyd, 2008)[45].

The second hypothesis (H2): "the organizational content does not impact the adoption of cloud computing in Jordan's pharmaceutical manufacturing firms. Results showed that Org. - cont. has an influence on cloud computing adoption in pharmaceutical industry; it was not as significant as the other two dimensions (Tech. and Env.). In this study, Org. - cont. factor included top management support, firm size, and technology readiness. As proposed by previous studies [ (Kim and Lee, 2008); (Yoon, T. , 2009)] [53]; [54], these factors could affect the process of adopting new technology. Top management support, firm size, competitive pressure and they have a significant effect on the adoption of cloud computing. Literature supports that top management support has influence on the adoption (Ramdani and Kawalek, 2009)[42]; without top management support, organizations are less likely to adopt new technologies.

This suggests that the supportive behavior of top management is an important constructor in influencing adoption strategies and outcomes ( J. Fowler and J. Floyd, 2008)[45]. (Gutierrez, A., et al , 2015)[21] Found that top 
management support was no longer a driving force for the adoption of cloud computing due to the growing awareness between business and IT managers regarding and also due to the potential benefits of cloud computing that outweigh the risks of its adoption (Alshamaila, Y., et al, 2013)[4].The big sized firms usually have more flexibility in their resources for the adoption of any new IT innovation. Therefore, there is a positive relationship between firm size and IT acceptance.

Another factor that can impact on the adoption of cloud computing is technical readiness. Technical readiness of organizations has positive influence on the adoption of cloud computing; the more readiness organization has, the more intention to adopt cloud computing (Sekaran, U , 2003)[44]. The findings of this study were supported by [ ( J. Fowler and J. Floyd, 2008); (Oliveira and Martins , 2010)]; [45]; [16]. This is mainly because organizations with high technological readiness are aware of current IT infrastructure potential, and limitations, organizations are willing to provide adequate training to enable the skills need to adopt cloud computing (Osama Harfoushi et al., 2016)[9]. Consequently, organizations which have technological readiness are better prepared for adopting cloud computing [ (Gutierrez, A., et al, 2015); ( Low, C., et al, 2011)];[21]; [18]. Technical readiness has no significantly impact on cloud computing adoption that is what the researchers found in this study. This is because the fact that organizations with developed hardware, software, and expertise resources may not effect by cloud computing adoption, it affect by the extent of implementation instead.

The third hypothesis (H3), "the environmental content does not impact the adoption of cloud computing in Jordan's pharmaceutical manufacturing firms was rejected as this factor was found to have a positive impact on the adoption of cloud computing. According to [ ( Low, C., et al, 2011); (Pallant, $\mathrm{J} \mathrm{,2005);} \mathrm{[18];} \mathrm{[49],} \mathrm{organizations} \mathrm{that}$ face intense competition resort to implement changes are more aggressively and respond more quickly in a competitive environment than others. When competitors implement cloud computing as a competitive tool, it builds a pressure on adopting of cloud computing therefore it continues in a competitive edge. According to (Zhu et al ., 2006) [55], competitive pressure compels companies to shift to cloud computing.

Trading partner pressure also has a positive impact on IT innovation adoption; this pressure can be either persuasive or imperative pressure. Organizations which adopting cloud computing technology are depending on whether they have been influenced by convincing power or through compulsory power, whereby the firm that has more bargaining power has requested that the firm with less bargaining power adopt cloud computing ( Low, C., et al, 2011)[18].Cloud computing technology needs comprehensive collaboration of all businesses partners in order to guarantee best practices and full benefits, therefore, cloud computing adopter's organizations forms networks with all participants to meet the customer needs and gain customer satisfaction (Gangwar, H.,et al , 2015) [7]. [ (Lin and Chen, 2012); (Alshamaila, Y., et al, 2013)]; [37]; [4], found that trading partner and competitive pressure were not statistically significant for adopting cloud computing.

\section{Conclusions and Future Work}

This research study is trying to test the proposed (TOE) framework illustrated in Figure 1. Results of this research demonstrated that the three dimensions of this framework (Tech., Org., and Env.) are interrelated to each other and significantly influence on the adoption of cloud computing in firms, in particular, Pharmaceutical manufacturing firms. Tech. - cont., was the most influential factor that influenced the adoption of cloud computing followed by Env.- cont., and finally Org. - cont.as supported by figures. The findings of this research study are crucial to information and technologies managers and workers as well as service providers. These findings also can support in developing plans and mechanisms for cloud computing adoption. The research model can help IT professionals and service providers in understanding clearly how and why Pharmaceutical manufacturing companies in Jordan choose to adopt cloud computing services. Moreover, firms can estimate whether these services, in reality, are compatible with their systems and how complex is the service implementation.

The future studies can harness the findings as a ground to implement a cloud computing in other business and manufacturing sectors and others as well. In this research study, a well - structured questionnaire was employed to collect data related to the influence of TOE framework on the adoption of cloud computing in Pharmaceutical manufacturing firms in Jordan context. In spite of the fact that this approach is valuable in understanding business-related decisions, it may not suitable to locate the right cause to the decision makers in firms to adopt or not adopt cloud computing. Furthermore, this study was carried out in Jordan where some pharmaceutical manufacturing firms, mostly the small size haven't a willingness yet to adopt cloud computing. For generalizability of the study results, further future studies are needed.

\section{REFERENCES}

[1] Pauly, M. T-Systems Cloud-Based Solutions for Business Applications. Cloud Computing: Principles and Paradigms.. s.1.: John Wiley \& Sons, Inc., Hoboken, 2011.

[2] Jin. (2007). A study of information technology adoption for 
small and medium sized enterprises strategic competitiveness. Wireless Communications, Networking and Mobile Computing, p.4342 - 6 .

[3] Science, I. P. (2014). Retrieved from: http://www.infosys.com/industries/life-sciences/white-pap ers/.

[4] Alshamaila, Y., Papagiannidis, S. and Li, F. (2013) Cloud Computing Adoption by SMEs in the North East of England: A Multi-Perspective Framework. Journal of Enterprise Information Management, 26, 250-275.

http://dx.doi.org/10.1108/17410391311325225

[5] Oliveira, T., Thomas, M. and Espadanal, M. (2014).Assessing the Determinants of Cloud Computing Adoption: An Analysis of the Manufacturing and Services Sectors. Information and Management, 51, 497-510. https://doi.org/10.1016/j.im.2014.03.006

[6] S. S. Bharadwaj and P. Lal. (2012). "Exploring the impact of Cloud Computing adoption on organizational flexibility: A client perspective," in 2012 International Conference on Cloud Computing Technologies, Applications and Management (ICCCTAM). pp. 121-131. https://doi.org/10.1109/ICCCTAM.2012.6488085

[7] Gangwar, H., Date, H. and Ramaswamy, R. (2015) Understanding Determinants of Cloud Computing Adoption Using an Integrated TAM-TOE Model. Journal of Enterprise Information Management, 28, 107-130.

[8] http://dx.doi.org/10.1108/JEIM-08-2013-0065

[9] G. Chao, A. Peng, A. Dutta, and A. Choudhary. (2014). "Exploring Critical Risks Associated with Enterprise Cloud Computing," in Cloud Comp, vol. 133, V. C. M. Leung and M. Chen, Eds. Cham: Springer International Publishing, pp. 132-141.

[10] Osama Harfoushi, Abdelhakim Akhorshaideh, Noor Aqqad, Marwa Al Janini, and Ruba Obaidat.(2016).Factors Affecting the Intension of Cloud Computing in Jordanian Hospitals. Communications and Network, Vol.08, No.2, pp.1 -14. https://doi.org/10.4236/cn.2016.82010.

[11] Mell and Grance. (2011). The NIST definition of cloud computing, recommendations of the National Institute of Standards and Technology. Special Publication, 800-145.

[12] M. Amini and N. Sadat Safavi, (2013)."Cloud Computing Transform the Way of IT Delivers Services to the Organizations," Int. J. Innov. Manag. Sci. Res., vol. 1, no. 61, pp. 1-5. https://doi.org/10.2139/ssrn.2256379

[13] Vouk, M.(2008)."Cloud Computing - Issues, Research and Implementations." J. Comput. Inf. Technol. https://doi.org/10.2498/cit.1001391.

[14] M. Zhou and R. Zhang. (2010). "Services in the cloud computing era: A survey," .... ... Symp. (IUCS), 2010 ..., pp. 40-46. https://doi.org/10.1109/IUCS.2010.5666772.

[15] Son, I., Lee, D., Lee, J., and Chang, Y. (2011). Understanding the impact of IT service innovation on firm performance: the case of cloud computing. Proceedings of the PACIS 2011. Retrieved from: http://aisel.aisnet.org/pacis2011/180. (Accessed 14th July 2012).

[16] McAfee, A. (2011). What every CEO needs to know about the Cloud. Harvard Business Review. November, pp124-132.

[17] Oliveira and Martins. (2010). Understanding e-business adoption across industries in European country Understanding e-business adoption across industries in European countries. Industrial Management \& Data Systems, 2010. 110(9): p. $1337-1354$ https://doi.org/10.1108/02635571011087428

[18] Alpar and Reeves. (1990).Predictors of MS/OR application in small businesses. Interfaces, 20(2). p. 2-11. https://doi.org/10.1287/inte.20.2.2.

[19] Low, C., Chen, Y. and Wu, M. (2011). Understanding the Determinants of Cloud Computing Adoption. Industrial Management \& Data Systems, 111, 1006-1023. https://doi.org/10.1108/02635571111161262

[20] Cegielski, C.G., Farmer, L.A., Wu, Y. and Hazen, B.T. (2012) Adoption of Cloud Computing Technologies in Supply Chains. The International Journal of Logistics Management, 23, 184-211. http://dx.doi.org/10.1108/09574091211265350

[21] Lian, J.W., Yen, D.C. and Wang, Y.T. (2014) .An Exploratory Study to Understand the Critical Factors Affecting the Decision to Adopt Cloud Computing in Taiwan Hospital. International Journal of Information Management, 34, 28-36. http://dx.doi.org/10.1016/j.ijinfomgt.2013.09.004

[22] Gutierrez, A., Boukrami, E. and Lumsden, R. (2015) .Technological, Organizational and Environmental Factors Influencing Managers' Decision to Adopt Cloud Computing in the UK. Journal of Enterprise Information Management, 28, 788-807.

https://doi.org/10.1108/JEIM-01-2015-0001

[23] Alkhater, N., Wills G. and Walters, R. (2014). Factors Influencing an Organization's Intention to Adopt Cloud Computing in Saudi Arabia. Proceedings of the IEEE 6th International Conference on Cloud Computing Technology and Science, Singapore, 15-18 December 2014, 1040-1044.

[24] Melville N, Ramirez R. (2008). Information technology innovation diffusion: An information requirements paradigm. Information Systems Journal.18 (3), 247-73. https://doi.org/10.1111/j.1365-2575.2007.00260.x

[25] M. W. Wang, O.-K. Lee and K. H. Lim. (2007). "Knowledge Management Systems Diffusion in Chinese Enterprises: A Multistage Approach with the TechnologyOrganization-Environment. Framework Proceedings," in Paper presented at the PACIS.

[26] Sonnenwald, D.H., Maglaughlin, K.L. and Whitton, M.C. (2001) Using Innovation Diffusion Theory to Guide Collaboration Technology Evaluation. Proceedings of the IEEE 10th International Workshop on Enabling Technologies, Work in Progress, Infrastructure for Collaborative Enterprises, Cambridge, 20-22 June 2001, 114-119. https://doi.org/10.1109/ENABL.2001.953399.

[27] Rogers, E. (2003) Diffusion of Innovations. 5th Edition, Free Press, New York.

[28] Berman, S., Kesterson-Townes, A. and Marchal, A. (2012) How Cloud Computing Enables Process and Business Model Innovation. Strategy and Leadership, 40, 27-35. 
https://doi.org/10.1108/10878571211242920.

[29] Dwivedi, Y.K. and Mustafee, N. (2010) It's Unwritten in the Cloud: The Technology Enablers for Realizing the Promise of Cloud Computing. Journal of Enterprise Information Management, 23, 673-679.

https://doi.org/10.1108/17410391011088583

[30] F. Thiesse at al. (2011). "The rise of the "next-generation bar code: an international RFID adoption study," Supply Chain Manag. An Int. J., vol. 16, no. 5, pp. 328-245.

[31] Peng, R., Xiong, L. and Yang, Z. (2012) Exploring Tourist Adoption of Tourism Mobile Payment: An Empirical Analysis. Journal of Theoretical and Applied Electronic Commerce Research, 7, 21-33.

https://doi.org/10.4067/S0718-18762012000100003.

[32] T. Greenhalgh, G. Robert, F. Macfarlane, P. Bate, and O. Kyriakidou. (2004)."Diffusion of Innovations in Service Organizations: Systematic Review and Recommendations," Milbank Q., vol. 82, no. 4, pp. 581-629. https://doi.org/10.1111/j.0887-378X.2004.00325.x

[33] P. Ifinedo. (2011). "An empirical analysis of factors influencing Internet/E-Business technologies adoption by SMEs in Canada," Int. J. Inf. Technol. Decis. Mak. vol. 10, no. 4, pp. 731-766.

https://doi.org/10.1142/S0219622011004543.

[34] S. S. Alam. (2009). "Adoption of Internet in Malaysian SMEs," J. Small Bus. Enterp. Dev., vol. 16, no. 2, pp. 240255. https://doi.org/10.1108/14626000910956038

[35] Miller, M. (2008). Cloud Computing: Web-Based Applications That Change the Way You Work and Collaborate Online. Que, Indiana.

[36] Azam Abdollahzadehgan, Ab Razak Che Hussin, Marjan Moshfegh, and Gohary, Mahyar Amini. (2014). The organizational critical success factors for adopting cloud computing in SMEs. Journal of information systems and innovation, 122(3), P.76- 74

[37] Feuerlicht, G. and Govardhan, S. (2010). Impact of Cloud Computing: Beyond a Technology Trend. Proceedings of the International Conference on Systems Integration, Oeconomica, Prague, 8-9 June 2010, 1-8.

[38] Lin, A. and Chen, N. (2012) Cloud Computing as an Innovation: Perception, Attitude, and Adoption. International Journal of Information Management, 32, 533-540. https://doi.org/10.1016/j.ijinfomgt.2012.04.001

[39] Lippert, S.K. and C. Govindarajulu. (2006).Technological, organizational, and environmental antecedents to web services adoption. Communications of the IIMA, 6(1): p. 146-157.

[40] Hsu, P.-F., K.L. Kraemer, and D. Dunkle. (2006).Determinants of e-business use in US firms. International Journal of Electronic Commerce, 10(4): p.

\section{9-45. https://doi.org/10.2753/JEC1086-4415100401}

[41] To, M. and Ngai, E. (2006) Predicting the Organizational Adoption of B2C E-Commerce: An Empirical Study. Industrial Management and Data Systems, 106, 1133-1147. https://doi.org/10.1108/02635570610710791

[42] Laforet, S. (2011) A Framework of Organizational Innovation and Outcomes in SMEs. International Journal of Entrepreneurial Behavior and Research, 17, 380-408. https://doi.org/10.1108/13552551111139638.

[43] Ramdani, B., Kawalek, P. and Lorenzo, O. (2009) Predicting SMEs' Adoption of Enterprise Systems. Journal of Enterprise Information Management, 22, 10-24. https://doi.org/10.1108/17410390910922796.

[44] Sekaran, U. and Bougie, R. (2013) Research Methods for Business. John Wiley \& Sons Ltd., Chichester.

[45] Sekaran, U. (2003) Research Methods for Business: A Skill Building Approach. 4th Edition, John Wiley \& Sons, Ltd., Hoboken.

[46] J. Fowler and J. Floyd. (2008). Survey research methods. Sage publications.

[47] Tweel, A. (2012). Examining the Relationship between Technological, Organizational, and Environmental Factors and Cloud Computing Adoption. Ph.D. Thesis, North central University, San Diego.

[48] Hair Jr., J.F., Anderson, R.E., Tatham, R.L. and Black, W.C. (1998) Multivariate Data Analysis. 5th Edition, Prentice Hall, Upper Saddle River.

[49] Creswell, J. (2009) Research Design: Qualitative, Quantitative, and Mixed Methods Approaches. 3rd Edition, Sage Publications, Thousand Oaks.

[50] Pallant, J. (2005). SPSS Survival Manual: A Step Guide to Data Analysis Using SPSS for Windows Version 12. Chicago: Open University Press.

[51] Ross, V.W. (2010) Factors Influencing the Adoption of Cloud Computing by Decision Making Mlla. University, Minneapolis.

[52] Lee, J. (2004) Discriminant Analysis of Technology Adoption Behavior: A Case of Internet Technologies in Small Businesses. Journal of Computer Information Systems, 44, 57-66.

[53] Sultan, N. (2011) Reaching for the "Cloud": How SMEs Can Manage. International Journal of Information Management, 31, 272-278. https://doi.org/10.1016/j.ijinfomgt.2010.08.001

[54] Zhu, K., Dong, S., Xu, S. and Kraemer, K. (2006) Innovation Diffusion in Global Contexts: Determinants of Post-Adoption Digital Transformation of European Companies. European Journal of Information Systems, 15, 601-616.https://doi.org/10.1057/palgrave.ejis.3000650. 